\title{
Drug dosing in the critically ill obese patient-a focus on sedation, analgesia, and delirium
}

\author{
Brian L. Erstad ${ }^{1}$ and Jeffrey F. Barletta ${ }^{2^{*}}$ (D)
}

\begin{abstract}
Practice guidelines provide clear evidence-based recommendations for the use of drug therapy to manage pain, agitation, and delirium associated with critical illness. Dosing recommendations however are often based on strategies used in patients with normal body habitus. Recommendations specific to critically ill patients with extreme obesity are lacking. Nonetheless, clinicians must craft dosing regimens for this population. This paper is intended to help clinicians design initial dosing regimens for medications commonly used in the management of pain, agitation, and delirium in critically ill patients with extreme obesity. A detailed literature search was conducted with an emphasis on obesity, pharmacokinetics, and dosing. Relevant manuscripts were reviewed and strategies for dosing are provided.
\end{abstract}

Keywords: Critical illness, Obesity, Pharmacokinetics, Drug-dosing

\section{Introduction}

Only 14 of the 100 most commonly used injectable medications in the adult intensive care units (ICUs) of an academic medical center had information in product labeling related to dosing obese patients. Of these 14 medications, only 6 had information considered to be minimally adequate for dosing [1]. Further, recommendations for medication dosing in critically ill obese patients are not available from adequately powered randomized studies with clinically relevant endpoints [2]. Prospective studies that are available typically used single-dose injections of medication in small numbers of patients in non-ICU settings. Additionally, available studies involving drug dosing in obese patients often evaluated pharmacokinetic parameters and/or surrogate markers as indicators of efficacy and adverse effects rather than clinically important outcomes. Regardless of suboptimal information, clinicians have to devise dosing regimens for critically ill obese patients that account for patient-specific issues. Therefore, dosing recommendations for patients with obesity usually are extrapolated from the physicochemical characteristics of medications in conjunction with data from pharmacokinetic, pharmacodynamic, and retrospective studies. The purpose of this paper is to provide a framework to help clinicians design initial dosing regimens for medications commonly used for the management of sedation, analgesia, and delirium in critically ill obese patients as discussed in evidence-based guidelines [3]. The focus will be on adult patients with more severe forms of obesity (e.g., body mass index (BMI) $\geq 40 \mathrm{~kg} / \mathrm{m}^{2}$ ), since such patients are typically limited in numbers in the studies used to formulate product labeling information and therefore most likely to receive inappropriate dosing if conventional doses are employed.

\section{Methodology}

A detailed literature search was performed using PubMed from inception to October 2019, using search terms from

\footnotetext{
* Correspondence: jbarle@midwestern.edu

2Department of Pharmacy Practice, Midwestern University, College of Pharmacy, 19555 N 59th Ave, Glendale, AZ 85308, USA

Full list of author information is available at the end of the article
}

(c) The Author(s). 2020 Open Access This article is licensed under a Creative Commons Attribution 4.0 International License, which permits use, sharing, adaptation, distribution and reproduction in any medium or format, as long as you give appropriate credit to the original author(s) and the source, provide a link to the Creative Commons licence, and indicate if changes were made. The images or other third party material in this article are included in the article's Creative Commons licence, unless indicated otherwise in a credit line to the material. If material is not included in the article's Creative Commons licence and your intended use is not permitted by statutory regulation or exceeds the permitted use, you will need to obtain permission directly from the copyright holder. To view a copy of this licence, visit http://creativecommons.org/licenses/by/4.0/. The Creative Commons Public Domain Dedication waiver (http://creativecommons.org/publicdomain/zero/1.0/) applies to the data made available in this article, unless otherwise stated in a credit line to the data. 
the following three categories: (1)obesity: "Obesity"[Mesh] OR "Overweight"[Mesh] OR "body composition" [MeSH Terms] OR "body weight change" OR "body size" OR "extreme obesity" OR "body fat" OR "body fatness," (2) pharmacokinetics and dosing: "Drug Monitoring"[Mesh] OR "Dose-Response Relationship, Drug"[Mesh] OR "pharmacokinetic considerations" OR "pharmacokinetic" OR "therapeutic drug monitoring" OR "drug monitoring" OR "drug dosing" OR "drug dose," and (3) the specific drug in question. The medications reviewed were those listed in recommendations from evidence-based guidelines and include the following: opioids, non-opioid analgesics, ketamine, propofol, dexmedetomidine, benzodiazepines, etomidate, haloperidol, and quetiapine. Results from the primary literature search were reviewed and pertinent articles were retained. Bibliographies were reviewed for articles that may have been missed by the primary literature search. Non-English articles and animal studies were not included. A comprehensive, online database was consulted for drug physicochemical properties (e.g., $\log P$ ) [4]. Suggestions were then formed using the available data based on the following prioritization strategy: outcome-based studies, pharmacokinetic studies, adverse effect profiles, and physiochemical properties. Because of the heterogeneity of study outcomes (i.e., pharmacokinetic-related, and clinical outcome) and the expected lack of information for many of the medications included, advanced statistical techniques such as meta-analysis was not performed.

When designing strategies for analgesia, sedation, or delirium, recommendations from evidence-based guidelines should be adhered to, similar to non-obese patients [3]. This includes targeting light sedation, use of validated assessment scales, daily sedative interruptions, spontaneous breathing trials, and delirium screening. When dosing medications, the choice of weight descriptor might seem to make little difference for weightbased dosing regimens because medications are dosed to clinical effect. However, particularly during medication initiation, there is the potential for under- or overdosing depending on the choice of weight descriptor. For example, the recommended starting rate of a propofol infusion for ICU sedation is $5 \mathrm{mcg} / \mathrm{kg} / \mathrm{min}$, as recommended in product information based on the clinical trials leading to drug approval, which likely involved normal weight individuals. Three critically ill patients all of the same age, height, sex, and co-morbidities, but weighing 70,100 , and $140 \mathrm{~kg}$, would receive starting doses ranging from 350 to $700 \mathrm{mcg} / \mathrm{min}$ based on ABW. (Additional file 1) While propofol (and other medications described in this paper) can be titrated to effect, large initial doses or infusion rates (based on ABW) can lead to adverse cardiovascular consequences, attainment of deeper levels of sedation, or doses that exceed those recommended for safety. Furthermore, the occurrence of an adverse drug event can lead to premature discontinuation of therapy and substitution with a less attractive alternative (i.e., benzodiazepine infusion). On the other extreme, under-dosing is a concern if ideal body weight (IBW) is inappropriately used for weight-based dosing regimens, since the calculation for IBW only considers height and not excess weight. This is particularly relevant for patients who receive etomidate prior to neuromuscular blocker therapy as under-dosing may lead an awake state during paralysis [5].

Several alternative size descriptors to actual body weight $(\mathrm{ABW})$ exist for weight-based dosing because it is known that lean mass does not increase in proportion to fat mass in obese subjects [6]. Ideal body weight only considers height and gender and thought to have originated from life insurance tables published more than 60 years ago. Unless otherwise stated, IBW refers to $50 \mathrm{~kg}+2.3 \mathrm{~kg}$ per inch above $60 \mathrm{in}$. for men or $45.5 \mathrm{~kg}+$ $2.3 \mathrm{~kg}$ per inch above $60 \mathrm{in}$. for women. Adjusted body weight refers to IBW $\mathrm{kg}+0.4$ (ABW $\mathrm{kg}-\mathrm{IBW} \mathrm{kg}$ ) for men or women. Body surface area (BSA) is considered the gold standard for dosing many chemotherapeutic medications and BMI is considered the gold standard for assessing obesity. Both however have limitations as size descriptors for medication dosing [7]. Lean body mass and allometric scaling are other size descriptors being investigated for medication dosing. More recent investigations evaluating lean body mass for medication dosing use separate equations for men and women and are susceptible to calculation errors if not calculated by software programs [8]. Further, equations to estimate lean body mass are not reliable in critically ill patients when compared to computed tomography as the gold standard [9]. Allometric scaling is a much simpler equation used to predict volume of distribution and clearance parameters from animals to humans and is currently being studied for its predictive value from normal weight to obese subjects [10].

Several assumptions or considerations underlie the recommendations in this paper. First, recommendations are limited to dosing based on ABW, or IBW or adjusted body weight equations recognizing the known limitations of each of these dosing descriptors [11]. For the purposes of this paper, adjusted body weight is considered to be roughly equivalent to lean body mass. The IBW and adjusted body equations have the advantages of being simple to calculate and well-known to most clinicians. While other size descriptors have theoretical appeal, none has demonstrated advantages for dosing obese patients based on clinical outcomes. Next, recorded ABW measurements assume accuracy (e.g., within $5 \%$ of $\mathrm{ABW}$ in kilograms) in weight measurements and consistent use of whatever weight descriptor (IBW, adjusted, actual) is chosen for dosing [12]. The 
recommendations in this paper also assume that other patient-specific considerations such as end-organ dysfunction (with impaired parent drug or active metabolite elimination) or actionable pharmacogenetic/pharmacogenomics profiles are considered in the final dosing recommendation. Finally, it should be noted that relatively few patients of extreme body weight served as the basis for dosing recommendations available in product labeling. A summary of these recommendations is listed in Fig. 1.

\section{Analgesia \\ Opioids}

All opioids are lipophilic with $\log P$ values between 1 and 2 for morphine, hydromorphone, and remifentanil and above 3 for fentanyl and sufentanil. This suggests that ABW might be preferred for single weight-based doses of fentanyl and sufentanil, in particular, given the expected increasing volume of distribution with increasing body weight. However, in studies suggesting a size descriptor for dosing opioids, recommendations were for IBW, lean body mass, or adjusted body weight as a preferred descriptor. While no prospective studies are available that compare weight-based dosing of opioids in obese and normal weight critically ill patients, prospective and retrospective studies performed in the emergency department and postoperative setting have consistently found large variations in opioid requirements and pain control in overweight and obese patients that had no relationship to ABW [1316]. Similarly, pharmacokinetic studies evaluating various opioids in the perioperative setting have found opioid doses based on ABW are likely to be excessive as evidenced by pharmacokinetic parameters and measured opioid concentrations [17-22]. One study noted decreased clearance of active morphine metabolites in morbidly obese compared to normal weight healthy volunteers, despite normal elimination of the parent compound. The clinical importance of this finding is unknown but could be of consequence with sustained dosing [23]. Pharmacodynamic alterations such as increased opioid sensitivity have also been described in select populations (e.g., geriatrics, obstructive sleep apnea) which can further increase the risk for respiratory depression [24, 25]. Guidelines promulgated by anesthesia associations in Great Britain and Ireland recommend the use of lean body weight for dosing opioids given the poor correlation between opioid concentrations and clinical effect and concerns related to overdosing until patients are alert allowing for dose titration [26]. Given the substantial variation in opioid pharmacokinetic parameters and clinical effects that are not related to $\mathrm{ABW}$, doses titrated to effect are recommended regardless of whether weight-based or non-weight-based dosing is used.

Summary For dosing opioids, incremental dosing titrated to clinical effect with consistent use of an ideal or adjusted body weight is suggested for weight-based dosing in obese patients, particularly in patients with more severe forms of obesity (e.g., BMI $\geq 40 \mathrm{~kg} / \mathrm{m}^{2}$ ).

\section{Non-opioid analgesics}

Non-opioid analgesics commonly administered to critically ill patients typically use non-weight-based dosing regimens based on information in product literature given the lack of prospective studies evaluating weightbased regimens. The few pharmacokinetic and pharmacodynamic studies evaluating the disposition of nonopioid agents, such as nonsteroidal anti-inflammatory

Analgesics

- Opioids: Incremental dosing with consistent use of an ideal or adjusted body weight is suggested.

- Non-opioid analgesics: No size descriptor recommendations are needed; standard doses would apply.

- Ketamine: Consistent use of an ideal or adjusted body weight is suggested for weight-based dosing in obese patients.

Sedatives

- Propofol: Weight-based dosing using ideal or adjusted body weight is preferred.

- Dexmedetomidine: Weight-based dosing using ideal or adjusted body weight is preferred.

- Midazolam: Consistent use of ideal or adjusted body weight is suggested for initial doses with supplemental doses as needed until the desired effect is achieved. Ideal or adjusted body weight should be used for continuous infusions.

- Etomidate: Actual body weight is suggested when $\mathrm{BMI}<40 \mathrm{~kg} / \mathrm{m}^{2}$. Adjusted or actual body weight is suggested when $B M I$ is $\geq 40 \mathrm{~kg} / \mathrm{m}^{2}$.

Anti-psychotics

- Haloperidol: Standard, non-weight-based doses are suggested.

- Quetiapine: Standard, non-weight-based doses are suggested.

Fig. 1 Summary of dosing recommendations for medications used in the management of sedation, analgesia, and delirium in critically ill patients with obesity. Unless otherwise indicated, these recommendations apply for patients with more severe forms of obesity (i.e., BMI $\geq 40 \mathrm{~kg} / \mathrm{m}^{2}$ ) 
drugs and acetaminophen, suggest variable pharmacokinetic parameters with little benefit for dose individualization based on weight. Furthermore, there are adverse effect concerns when increasing doses beyond those needed to reach the analgesic ceiling effect [27-29]. Some adverse effects (e.g., acetaminopheninduced liver injury) may be more frequent in patients with obesity [30, 31]. Therefore, no size descriptor recommendation is needed for analgesic agents administered by non-weight-based dosing regimens.

\section{Ketamine}

Ketamine dosing varies based on the clinical indication with lower doses being utilized for the provision of analgosedation in mechanically ventilated patients (versus status epilepticus) [32]. Even within studies specific to this indication, there is wide divergence in dosing strategies and obese patients are not well represented. Thus, dosing recommendations in patients with more severe forms of obesity are dependent on extrapolations from ketamine's physicochemical and pharmacokinetic characteristics. Substantial lipophilicity $(\log$ P 3.1$)$ with a large volume of distribution, rapid clearance (approximately $18 \mathrm{~mL} / \mathrm{min} / \mathrm{kg}$ ) approximating hepatic blood flow, and active metabolites all complicate potential dosing recommendations for ketamine, particularly with sustained dosing in critically ill patients. Studies in animals and healthy volunteers have demonstrated that ketamine has a large steady state volume of distribution of approximately 2.5 to $5 \mathrm{~L} / \mathrm{kg}$ with estimates of initial (alpha) distribution half-life ranging from 2 to $20 \mathrm{~min}$ and terminal half-life ranging from 2.5 to $3 \mathrm{~h}$ [33, 34]. A study in critically ill patients with brain or spinal cord injuries found increases in ketamine's volume of distribution and clearance. The increase in volume of distribution was more than three times that found in studies involving normal healthy volunteers or patients undergoing surgery. Clearance was also increased in critically ill patients, but less so than the volume of distribution, resulting in a terminal half-life of approximately $5 \mathrm{~h}$ [35]. With single or isolated doses, the alpha half-life corresponds to termination of analgesic (low dose) or anesthetic (high dose) actions of ketamine by redistribution from the CNS to peripheral tissues. However, with sustained intermittent intravenous injections or continuous infusions of ketamine, accumulation of both parent drug and active metabolite norketamine occurs until steady state conditions occur. Norketamine has not only about one-third the potency of the parent compound, but also has slower elimination that increases the time to reach steady state. Therefore, ketamine administered by continuous intravenous infusion will likely need decreases in dose over time in order to maintain the same clinical effect.
With respect to loading doses, $\mathrm{ABW}$ is appealing as a size descriptor given the lipophilicity of ketamine, since clinical effect in this situation is largely a function of the drug's volume of distribution. This belies the substantial inter-patient variability and therefore predictability of volume of distribution in a critically ill patient. Further, clearance of ketamine, which becomes more of an issue with sustained dosing, is a function of lean body mass and not likely to increase in proportion to fat mass in patients with obesity. These factors in conjunction with the challenges related to dosing a drug with an active metabolite suggest the use of an ideal or adjusted body weight is preferable for weight-based dosing calculations due to adverse effect concerns associated with over-dosing.

Summary For dosing ketamine, consistent use of an ideal or adjusted body weight is suggested for weightbased dosing in obese patients, particularly in patients with more severe forms of obesity (e.g., BMI $\geq 40 \mathrm{~kg} / \mathrm{m}^{2}$ ).

\section{Sedation \\ Propofol}

Propofol is one of the most widely used sedatives for the facilitation of mechanical ventilation because of its quick onset and short duration of effect. Propofol has a large volume of distribution $(60 \mathrm{~L} / \mathrm{kg})$ with a $\log P$ of 4.16 indicating a high degree of lipophilicity. Several studies have evaluated propofol-dosing strategies in the operating room but there are no data specific to the ICU. Thus, when extrapolating these data to the ICU setting, differences in therapeutics goals, administration techniques, and treatment duration must be considered. One study evaluated propofol for maintenance of anesthesia in a cohort of patients with a mean weight of $115 \pm 21$ $\mathrm{kg}$ [36]. In this study, both clearance and volume of distribution were significantly correlated with weight $(r=$ 0.76 and 0.69 , respectively) indicating $\mathrm{ABW}$ may be the most suitable weight measure for maintenance of anesthesia. A second study described the relationship between propofol concentrations and weight and concluded plasma concentrations may be dependent on ABW $(r=0.646, p<.001)$ [37]. This study however included primarily non-obese individuals $(\mathrm{ABW}=58 \pm 13$ $\mathrm{kg}$ ) and patients with more extreme forms of obesity were not represented.

Other studies evaluating propofol for anesthesia induction have suggested alternatives such as lean body weight or corrected body weight as the preferred metric for dosing secondary to the nonlinear relationship that exists in obese patients between ABW and clearance (Additional file 2) [38-45]. One study described a pharmacokinetic model in obesity that replaced $\mathrm{ABW}$ with lean body weight and simulated concentrations were higher with ABW-based dosing [43]. A second study 
randomized obese patients $\left(\mathrm{BMI}>35 \mathrm{~kg} / \mathrm{m}^{2}\right)$ receiving propofol for anesthesia induction based on either $A B W$ or lean body weight-based dosing; pharmacokinetic and pharmacodynamic effects were then compared to a cohort of non-obese patients $\left(\mathrm{BMI}<25 \mathrm{~kg} / \mathrm{m}^{2}\right)$ [39]. In this study, both clearance (lean body weight-dosing, $9.15 \mathrm{~L} /$ min, ABW-dosing $10 \mathrm{~L} / \mathrm{min}$ versus $4.11 \mathrm{~L} / \mathrm{min}, p<.01$ ) and volume of the peripheral compartment (lean body weight-dosing, $84.2 \mathrm{~L}, \mathrm{ABW}$-dosing, $73.2 \mathrm{~L}$ versus $46.9 \mathrm{~L}$, $p<.01)$ were greater in the patients with obesity. Patients who were dosed based on ABW, however, had significantly lower bispectral index values indicating a heightened anesthetic response and increased CNS sensitivity. Dosing using lean body weight was therefore recommended.

Other studies have accounted for the non-linear relationship between weight and clearance using allometric dose scalers (e.g., $\mathrm{Cl}$ scaled by ABW to a power of " $x$ ") [46-48]. These models, however, have not been wellvalidated particularly in critically ill obese patients and are not commonly used in the clinical setting. Furthermore, the inherent differences in the endpoints targeted with each strategy (i.e., induction of anesthesia for a surgery vs. mild-to-moderate sedation for comfort) are noteworthy making the extrapolation of these models limited.

The most common and often dose-limiting adverse effect with propofol is hypotension. One study identified obesity as a risk factor for hypotension in trauma patients who received propofol in the emergency department [49]. In this study, obesity (BMI $\geq 30 \mathrm{~kg} / \mathrm{m}^{2}$ ) was associated with more than a 2-fold increase in hypotension [OR $(95 \% \mathrm{CI})=2.66(1.08-6.55)]$. This is likely related to the higher doses administered or the use of ABW-based dosing in the obese cohort.

Summary Although some studies support the use of ABW-based dosing for propofol, the relationship between weight and pharmacokinetic variables such as clearance is nonlinear. Dosing using $\mathrm{ABW}$ may result in supratherapeutic concentrations. Thus, weight-based dosing using either IBW or adjusted body weight is preferred.

\section{Dexmedetomidine}

Pharmacokinetic studies of dexmedetomidine in critically ill patients have revealed a volume of distribution of $104 \mathrm{~L}$ and clearance of $39 \mathrm{~L} / \mathrm{h}$ with a substantial amount of interpatient variability [50]. Hypoalbuminemia, endorgan damage, and cardiac output may contribute to this variability [51]. The $\log P$ for dexmedetomidine is 3.39 .

Studies evaluating the impact of obesity on dexmedetomidine pharmacokinetics are beginning to emerge but data specific to the ICU population are limited (Additional file 2). Shortcomings related to the study setting (i.e., operating room versus ICU) would apply. One study evaluated the pharmacokinetics of dexmedetomidine in morbidly obese patients undergoing laparoscopic surgery [52]. There was no difference in volume of distribution when normalized to ABW $(2.48 \pm 0.47$ vs. $2.38 \pm 0.72 \mathrm{~L} / \mathrm{kg} ; p=.72$ ) but clearance was significantly lower with obesity $(0.47 \pm 0.07$ vs. $0.64 \pm 0.09 \mathrm{~L} / \mathrm{kg} / \mathrm{h}$; $\mathrm{p}<.01$, based on $\mathrm{ABW})$. As a result, area under the curve was significantly larger $(2174 \pm 335$ vs. $1594 \pm 251$ ng $\mathrm{L} / \mathrm{h}, p<.01)$. A second study, also conducted in the operating room setting, revealed dexmedetomidine dosing based on a linear ABW-based strategy led to higher serum concentrations in obese compared to non-obese patients [53]. This was presumed to be due to both decreased distribution into adipose tissue and impaired clearance associated with fat mass. A follow-up study by the same research team however concluded fat mass did not influence dexmedetomidine clearance [54]. Nevertheless, lean body weight was the preferred weight measure for dosing.

Summary The use of ABW to calculate either bolus doses or infusion rates may lead to supratherapeutic concentrations. Weight-based dosing for dexmedetomidine using either IBW or adjusted body weight is suggested.

\section{Benzodiazepines}

Midazolam is a highly lipophilic benzodiazepine (log $P=3.33$ ) with a volume of distribution of $2 \mathrm{~L} / \mathrm{kg}$. Initial studies in healthy volunteers demonstrated a significantly higher volume of distribution, even after controlling for $\mathrm{ABW}$, in obese subjects $(1.74 \pm 0.11$ vs. $2.66 \pm$ $0.16 \mathrm{~L} / \mathrm{kg} ; p<.001$ ) [55] (Additional file 2). Total clearance, however, was not impacted by obesity (non-obese, $530 \pm 34$ vs. obese, $472 \pm 38 \mathrm{ml} / \mathrm{min} ; p=\mathrm{NS}$ ). Overall, this led to a prolonged half-life with obesity $(2.27 \pm 0.3$ vs. $5.94 \pm 0.85 \mathrm{~h} ; p<.001)$. A second study evaluated midazolam pharmacokinetics in obese patients undergoing bariatric surgery [56]. In this study, there was a linear increase in central volume of distribution with increased $\mathrm{ABW}$ and peripheral volume of distribution increased in a non-linear manner. Clearance was unaffected by $\mathrm{ABW}$.

Summary The data suggest larger initial doses may be necessary in obese patients because of the increased volume of distribution observed in these patients. Midazolam clearance however does not change with increasing $\mathrm{ABW}$ thus the potential for accumulation and supratherapeutic concentrations exists with weight-based dosing using $\mathrm{ABW}$. Because of concerns with adverse hemodynamic effects with larger doses of midazolam, a safer approach would be to use IBW or adjusted body 
weight for initial doses with smaller supplemental doses administered as needed until the desired effect is achieved. Adjusted body weight or IBW should be used to calculate doses for continuous infusions.

\section{Etomidate}

Most of the recent research concerning the use of etomidate in critically ill patients involves the administration of single intravenous bolus doses for rapid sequence intubation (RSI). Irrespective of the favorable hemodynamic adverse effect profile of etomidate in critically ill patients, there is ongoing debate of the use of etomidate for RSI because of potential adrenal insufficiency related to inhibition of 11 beta-hydroxylase [57, 58]. Despite these concerns, etomidate continues to be used and investigated as an agent for RSI with a usual dose of $0.3 \mathrm{mg} / \mathrm{kg}$ based on ABW $[59,60]$. Etomidate has a large volume of distribution with relatively rapid metabolism by the liver, but with plasma concentrations that are poorly correlated with pharmacodynamic measures of clinical response [61]. In light of etomidate's large volume of distribution, there is a concern of under-dosing in more obese patients, which could lead to patient awareness during concomitant paralysis with a neuromuscular blocker [62]. In one prospective study evaluating an RSI protocol, 5 of the 10 patients interviewed remembered aspects of the intubation procedure suggesting inadequate sedation [5]. Concerns of inadequate dosing would outweigh toxicity concerns of higher doses based on ABW in most obese patients. However, there are practical concerns related to etomidate vial and syringe sizes available in bedside RSI kits that may hinder timely administration of large etomidate doses based on $\mathrm{ABW}$. Re-dosing of etomidate postintubation is another important consideration since the duration of action of etomidate is substantially shorter than that of commonly used nondepolarizing neuromuscular blockers such as rocuronium [63].

Summary For dosing etomidate, $\mathrm{ABW}$ is suggested for weight-based dosing in obese patients with a BMI $<40$ $\mathrm{kg} / \mathrm{m}^{2}$. Dosing using either adjusted or ABW is suggested in patients with more severe forms of obesity (e.g., $B M I \geq 40 \mathrm{~kg} / \mathrm{m}^{2}$ ).

\section{Antipsychotics Haloperidol}

Despite the limited role antipsychotics have in evidencebased guidelines for both the prevention and treatment of delirium, they are still widely administered for this indication $[3,64,65]$. Haloperidol has a volume of distribution of $1260 \mathrm{~L}$ and a $\log P$ of 3.77 suggesting distribution into adipose tissue [66]. One study evaluating haloperidol pharmacokinetics in psychiatric patients reported a non-linear relationship between body weight and clearance [67]. Nevertheless, a troublesome adverse effect with haloperidol is QTc prolongation, which can be associated with dose. Further, a higher incidence of torsades de pointes has been found in patients who receive at least $35 \mathrm{mg}$ of haloperidol in $24 \mathrm{~h} \mathrm{[68].} \mathrm{The} \mathrm{inci-}$ dence of torsades de pointes was more prominent when this dose was given in less than $6 \mathrm{~h}$. Caution with larger doses is therefore warranted.

Summary Although haloperidol has pharmacokinetic properties that favor distribution into adipose tissue, there are severe adverse reactions associated with large doses. Standard doses of haloperidol that can be titrated to effect are suggested. Routine monitoring for QTc prolongation should be conducted.

\section{Quetiapine}

Quetiapine is an atypical antipsychotic frequently considered in place of haloperidol because of a more favorable adverse effect profile. Quetiapine also has a large volume of distribution $(10 \mathrm{~L} / \mathrm{kg})$ with a $\log P$ of 2.81 . There are no data evaluating quetiapine dosing in obese critically ill patients. Pharmacokinetic studies in healthy volunteers or individuals with psychiatric disorders have not reported significant variance secondary to weight [69]. Few, if any of these patients however would be expected to have extreme forms of obesity.

Summary Standard, non-weight-based doses of quetiapine consistent with that utilized in non-obese patients should be considered.

\section{Conclusion}

For obese patients, there is no high-level clinical evidence available to help design dosing regimens for sedation, analgesia, and delirium as recommended in critical care practice guidelines. Based on pharmacokinetic studies, the relationship between ABW and pharmacokinetic variables such as volume of distribution and clearance is not linear for many medications used in the management of pain, agitation, and delirium. For such medications, standard, non-weight-based dosing, or weight-based dosing using either IBW or adjusted body weight, is appropriate. Weight-based dosing using ABW is discouraged because dose proportionality between pharmacokinetic parameters and ABW is rarely encountered. In the rare instances where dose proportionality is evident, potential adverse effects (associated with large doses) remain an important consideration. Clinicians should utilize smaller doses that can be repeated incrementally and titrated to clinical effect when applicable. Consultation with a clinical pharmacist can be useful when crafting dosing regimens in critically ill patients with extreme obesity. 


\section{Supplementary information}

Supplementary information accompanies this paper at https://doi.org/10. 1186/s13054-020-03040-z.

Additional file 1. Hypothetical examples of initial doses in three male patients with different weights using ideal body weight, adjusted body weight and actual body weight. For each example, height is estimated to be $5^{\prime} 9^{\prime \prime}$ and adjusted body weight is calculated using a correction factor of 0.4 .

Additional file 2. Clinical and pharmacokinetic studies involving sedatives.

\section{Abbreviations}

ABW: Actual body weight; BMI: Body mass index; BSA: Body surface area; IBW: Ideal body weight; ICU: Intensive care unit

\section{Acknowledgements}

Not applicable

\section{Authors' contributions}

BLE: Development of manuscript outline, literature search, literature evaluation, crafting of recommendations, manuscript preparation, and critical review. JFB: Development of manuscript outline, literature search, literature evaluation, crafting of recommendations, manuscript preparation, and critical review. The authors read and approved the final manuscript.

\section{Funding}

None

\section{Availability of data and materials \\ Not applicable}

\section{Ethics approval and consent to participate}

Not applicable

\section{Consent for publication}

Not applicable

\section{Competing interests}

BLE: No conflicts of interest.

JFB: Consultant for Wolters Kluwer.

\section{Author details}

${ }^{1}$ Department of Pharmacy Practice \& Science, University of Arizona, College of Pharmacy, 1295 N Martin Ave, PO Box 210202, Tucson, AZ 85721, USA. ${ }^{2}$ Department of Pharmacy Practice, Midwestern University, College of Pharmacy, 19555 N 59th Ave, Glendale, AZ 85308, USA.

\section{Received: 10 March 2020 Accepted: 27 May 2020}

\section{Published online: 08 June 2020}

\section{References}

1. Eastman C, Erstad BL. Availability of information for dosing commonly used medications in special ICU populations. Am J Health-Syst Pharmacy. 2020; 77(7):529-34.

2. Erstad BL. Designing drug regimens for special intensive care unit populations. World J Critical Care Med. 2015;4(2):139-51.

3. Devlin JW, Skrobik Y, Gelinas C, Needham DM, Slooter AJC, Pandharipande PP, et al. Clinical practice guidelines for the prevention and management of pain, agitation/sedation, delirium, immobility, and sleep disruption in adult patients in the ICU. Crit Care Med. 2018;46(9):e825-e73.

4. Wishart DS, Feunang YD, Guo AC, Lo EJ, Marcu A, Grant JR, et al. DrugBank 5.0: a major update to the DrugBank database for 2018. Nucleic Acids Res. 2018;46(D1):D1074-82. https://www.drugbank.ca/. Accessed Oct 2019.

5. Kimball D, Kincaide RC, Ives C, Henderson S. Rapid sequence intubation from the Patient's perspective. West J Emerg Med. 2011;12(4):365-7.

6. McLeay SC, Morrish GA, Kirkpatrick CM, Green B. The relationship between drug clearance and body size: systematic review and metaanalysis of the literature published from 2000 to 2007. Clin Pharmacokinet. 2012;51(5):319-30
7. Green B, Duffull SB. What is the best size descriptor to use for pharmacokinetic studies in the obese? Br J Clin Pharmacol. 2004:58(2):119-33.

8. Janmahasatian S, Duffull SB, Ash S, Ward LC, Byrne NM, Green B. Quantification of lean bodyweight. Clin Pharmacokinet. 2005:44(10):1051-65.

9. Moisey LL, Mourtzakis M, Kozar RA, Compher C, Heyland DK. Existing equations to estimate lean body mass are not accurate in the critically ill: Results of a multicenter observational study. Clin Nutri (Edinburgh, Scotland). 2017;36(6):1701-6.

10. Mahmood I. Prediction of clearance and volume of distribution in the obese from normal weight subjects : an allometric approach. Clin Pharmacokinet. 2012:51(8):527-42.

11. Pai MP. Drug dosing based on weight and body surface area: mathematical assumptions and limitations in obese adults. Pharmacotherapy. 2012;32(9):856-68.

12. Jensen GL, Friedmann JM, Henry DK, Skipper A, Beiler E, Porter C, et al. Noncompliance with body weight measurement in tertiary care teaching hospitals. JPEN J Parenter Enteral Nutr. 2003;27(1):89-90.

13. Bennett R, Batenhorst R, Graves DA, Foster TS, Griffen WO, Wright BD. Variation in postoperative analgesic requirements in the morbidly obese following gastric bypass surgery. Pharmacotherapy. 1982;2(1):50-3.

14. Patanwala AE, Holmes KL, Erstad BL. Analgesic response to morphine in obese and morbidly obese patients in the emergency department. Emerg Med J. 2014;31(2):139-42.

15. Rand CSW, Kuldau JM, Yost RL. Obesity and post-operative pain. J Psychosom Res. 1985;29:43-8.

16. Xia S, Choe D, Hernandez L, Birnbaum A. Does initial hydromorphone relieve pain best if dosing is fixed or weight based? Annals of emergency medicine. 2014;63(6):692-8.e4.

17. Egan TD, Huizinga B, Gupta SK, Jaarsma RL, Sperry RJ, Yee JB, et al. Remifentanil pharmacokinetics in obese versus lean patients. Anesthesiology. 1998;89(3):562-73.

18. Perus O, Marsot A, Ramain E, Dahman M, Paci A, Raucoules-Aime M, et al. Performance of alfentanil target-controlled infusion in normal and morbidly obese female patients. Br J Anaesth. 2012;109(4):551-60.

19. Schwartz AE, Matteo RS, Ornstein E, Young WL, Myers KJ. Pharmacokinetics of sufentanil in obese patients. Anesth Analg. 1991;73(6):790-3.

20. Shibutani K, Inchiosa MA Jr, Sawada K, Bairamian M. Accuracy of pharmacokinetic models for predicting plasma fentanyl concentrations in lean and obese surgical patients: derivation of dosing weight ("pharmacokinetic mass"). Anesthesiology. 2004;101(3):603-13.

21. Shibutani K, Inchiosa MA Jr, Sawada K, Bairamian M. Pharmacokinetic mass of fentanyl for postoperative analgesia in lean and obese patients. $\mathrm{Br}$ J Anaesth. 2005;95(3):377-83.

22. Slepchenko G, Simon N, Goubaux B, Levron JC, Le Moing JP, RaucoulesAime M. Performance of target-controlled sufentanil infusion in obese patients. Anesthesiology. 2003;98(1):65-73

23. de Hoogd S, Valitalo PAJ, Dahan A, van Kralingen S, Coughtrie MMW, van Dongen EPA, et al. Influence of morbid obesity on the pharmacokinetics of morphine, morphine-3-glucuronide, and morphine-6-glucuronide. Clin Pharmacokinet. 2017:56(12):1577-87.

24. Cozowicz C, Chung F, Doufas AG, Nagappa M, Memtsoudis SG. Opioids for acute pain management in patients with obstructive sleep apnea: a systematic review. Anesth Analg. 2018;127(4):988-1001.

25. Scott JC, Stanski DR. Decreased fentanyl and alfentanil dose requirements with age. A simultaneous pharmacokinetic and pharmacodynamic evaluation. J Pharmacol Exp Ther. 1987:240(1):159-66.

26. Nightingale CE, Margarson MP, Shearer E, Redman JW, Lucas DN, Cousins $J M$, et al. Peri-operative management of the obese surgical patient 2015: association of anaesthetists of Great Britain and Ireland society for obesity and bariatric anaesthesia. Anaesthesia. 2015;70(7):859-76.

27. Abernethy DR, Greenblatt DJ. Ibuprofen disposition in obese individuals. Arthritis Rheum. 1985;28(10):1117-21.

28. Allegaert $\mathrm{K}$, Olkkola KT, Owens KH, Van de Velde M, de Maat MM, Anderson BJ. Covariates of intravenous paracetamol pharmacokinetics in adults. BMC Anesthesiol. 2014:14:77.

29. Motov S, Yasavolian M, Likourezos A, Pushkar I, Hossain R, Drapkin J, et al. Comparison of intravenous ketorolac at three single-dose regimens for treating acute pain in the emergency department: a randomized controlled trial. Ann Emerg Med. 2017;70(2):177-84.

30. Allard J, Le Guillou D, Begriche K, Fromenty B. Drug-induced liver injury in obesity and nonalcoholic fatty liver disease. Adv Pharmacol (San Diego, Calif). 2019;85:75-107. 
31. Chomchai S, Chomchai C. Being overweight or obese as a risk factor for acute liver injury secondary to acute acetaminophen overdose. Pharmacoepidemiol Drug Saf. 2018;27(1):19-24.

32. Hurth KP, Jaworski A, Thomas KB, Kirsch WB, Rudoni MA, Wohlfarth KM. The Reemergence of ketamine for treatment in critically ill adults. Critical Care Med. 2020:48(6):899-911.

33. Clements JA, Nimmo WS. Pharmacokinetics and analgesic effect of ketamine in man. Br J Anaesth. 1981;53(1):27-30.

34. Domino EF. Taming the ketamine tiger. 1965. Anesthesiology. 2010;113(3): 678-84.

35. Hijazi Y, Bodonian C, Bolon M, Salord F, Boulieu R. Pharmacokinetics and haemodynamics of ketamine in intensive care patients with brain or spinal cord injury. Br J Anaesth. 2003;90(2):155-60.

36. Servin F, Farinotti R, Haberer JP, Desmonts JM. Propofol infusion for maintenance of anesthesia in morbidly obese patients receiving nitrous oxide. A clinical and pharmacokinetic study. Anesthesiology. 1993;78(4):657-65.

37. Hirota $K$, Ebina $T$, Sato $T$, Ishihara $H$, Matsuki A. Is total body weight an appropriate predictor for propofol maintenance dose? Acta Anaesthesiol Scand. 1999:43(8):842-4.

38. Chassard D, Berrada K, Bryssine B, Guiraud M, Bouletreau P. Influence of body compartments on propofol induction dose in female patients. Acta Anaesthesiol Scand. 1996;40(8 Pt 1):889-91.

39. Dong D, Peng X, Liu J, Qian H, Li J, Wu B. Morbid obesity alters both pharmacokinetics and pharmacodynamics of propofol: dosing recommendation for anesthesia induction. Drug Metabolism Disposition. 2016;44(10):1579-83

40. Ingrande J, Brodsky JB, Lemmens HJ. Lean body weight scalar for the anesthetic induction dose of propofol in morbidly obese subjects. Anesth Analg. 2011;113(1):57-62.

41. Leslie K, Crankshaw DP. Lean tissue mass is a useful predictor of induction dose requirements for propofol. Anaesth Intensive Care. 1991;19(1):57-60.

42. Lind $L$, Johansson $S$, Ekman $K$. The influence of obesity and fat distribution on induction and maintenance doses of propofol. (short communication). Ups J Med Sci. 1993:98(2):187-8.

43. McLeay SC, Morrish GA, Kirkpatrick CM, Green B. Encouraging the move towards predictive population models for the obese using propofol as a motivating example. Pharm Res. 2009;26(7):1626-34.

44. Araujo AM, Machado HS, Falcao AC, Soares-da-Silva P. Reliability of bodyweight scalars on the assessment of propofol induction dose in obese patients. Acta Anaesthesiol Scand. 2018;62(4):464-73.

45. Lam F, Liao CC, Lee YJ, Wang W, Kuo CJ, Lin CS. Different dosing regimens for propofol induction in obese patients. Acta Anaesthesiol Taiwanica : Off J Taiwan Soc Anesthesiol. 2013;51(2):53-7.

46. Cortinez LI, Anderson BJ, Penna A, Olivares L, Munoz HR, Holford NH, et al. Influence of obesity on propofol pharmacokinetics: derivation of a pharmacokinetic model. Br J Anaesth. 2010;105(4):448-56.

47. Eleveld DJ, Proost JH, Cortinez LI, Absalom AR, Struys MM. A genera purpose pharmacokinetic model for propofol. Anesth Analg. 2014;118(6): 1221-37.

48. van Kralingen S, Diepstraten J, Peeters MY, Deneer VH, van Ramshorst B Wiezer RJ, et al. Population pharmacokinetics and pharmacodynamics of propofol in morbidly obese patients. Clin Pharmacokinet. 2011;50(11):739-50.

49. Shearin $A E$, Patanwala AE, Tang A, Erstad BL. Predictors of hypotension associated with propofol in trauma patients. J Trauma Nurs. 2014;21(1):4-8.

50. Valitalo PA, Ahtola-Satila T, Wighton A, Sarapohja T, Pohjanjousi P, Garratt C. Population pharmacokinetics of dexmedetomidine in critically ill patients. Clinical Drug Investigation. 2013;33(8):579-87.

51. Weerink MAS, Struys M, Hannivoort LN, Barends CRM, Absalom AR, Colin P. Clinical pharmacokinetics and pharmacodynamics of dexmedetomidine. Clin Pharmacokinet. 2017;56(8):893-913.

52. Xu B, Zhou D, Ren L, Shulman S, Zhang X, Xiong M. Pharmacokinetic and pharmacodynamics of intravenous dexmedetomidine in morbidly obese patients undergoing laparoscopic surgery. J Anesth. 2017;31(6):813-20.

53. Cortinez LI, Anderson BJ, Holford NH, Puga V, de la Fuente $\mathrm{N}$, Auad H, et al. Dexmedetomidine pharmacokinetics in the obese. Eur J Clin Pharmacol. 2015;71(12):1501-8.

54. Rolle A, Paredes S, Cortinez LI, Anderson BJ, Quezada N, Solari S, et al. Dexmedetomidine metabolic clearance is not affected by fat mass in obese patients. Br J Anaesth. 2018;120(5):969-77.
55. Greenblatt DJ, Abernethy DR, Locniskar A, Harmatz JS, Limjuco RA, Shader RI. Effect of age, gender, and obesity on midazolam kinetics. Anesthesiology. 1984;61(1):27-35.

56. Brill MJ, van Rongen A, Houwink AP, Burggraaf J, van Ramshorst B, Wiezer $\mathrm{RJ}$, et al. Midazolam pharmacokinetics in morbidly obese patients following semi-simultaneous oral and intravenous administration: a comparison with healthy volunteers. Clin Pharmacokinet. 2014;53(10):931-41.

57. Katz J, Greenberg S. Etomidate is NOT a first-line induction agent in critically ill patients: primum non nocere-above all, do no harm. Crit Care Med. 2018; 46(9):1495-6.

58. Lynde GC, Jabaley CS. Etomidate is a first-line induction agent in critically ill patients. Crit Care Med. 2018;46(9):1492-4

59. Gu WJ, Wang F, Tang L, Liu JC. Single-dose etomidate does not increase mortality in patients with sepsis: a systematic review and meta-analysis of randomized controlled trials and observational studies. Chest. 2015:147(2): 335-46.

60. Jabre P, Combes X, Lapostolle F, Dhaouadi M, Ricard-Hibon A, Vivien B, et al. Etomidate versus ketamine for rapid sequence intubation in acutely ill patients: a multicentre randomised controlled trial. Lancet (London, England). 2009;374(9686):293-300.

61. Kaneda K, Yamashita S, Woo S, Han TH. Population pharmacokinetics and pharmacodynamics of brief etomidate infusion in healthy volunteers. J Clin Pharmacol. 2011;51(4):482-91.

62. Traylor BR, Patanwala AE, Sakles JC, Erstad BL. Under-dosing of etomidate for rapid sequence intubation in the emergency department. Curr Drug Saf. 2013;8(4):253-6.

63. Amini A, Faucett EA, Watt JM, Amini R, Sakles JC, Rhee P, et al. Effect of a pharmacist on timing of postintubation sedative and analgesic use in trauma resuscitations. Am J Health-Syst Pharmacy. 2013;70(17):1513-7.

64. Patel RP, Gambrell M, Speroff T, Scott TA, Pun BT, Okahashi J, et al. Delirium and sedation in the intensive care unit: survey of behaviors and attitudes of 1384 healthcare professionals. Crit Care Med. 2009:37(3):825-32.

65. Swan JT, Fitousis K, Hall JB, Todd SR, Turner KL. Antipsychotic use and diagnosis of delirium in the intensive care unit. Critical care (London, England). 2012:16(3):R84.

66. Kudo S, Ishizaki T. Pharmacokinetics of haloperidol: an update. Clin Pharmacokinet. 1999:37(6):435-56.

67. Yukawa E, Hokazono T, Yukawa M, Ichimaru R, Maki T, Matsunaga K, et al. Population pharmacokinetics of haloperidol using routine clinical pharmacokinetic data in Japanese patients. Clin Pharmacokinet. 2002;41(2): 153-9.

68. Sharma ND, Rosman HS, Padhi ID, Tisdale JE. Torsades de Pointes associated with intravenous haloperidol in critically ill patients. Am J Cardiol. 1998; 81(2):238-40.

69. DeVane $\mathrm{CL}$, Nemeroff $\mathrm{CB}$. Clinical pharmacokinetics of quetiapine: an atypical antipsychotic. Clin Pharmacokinet. 2001:40(7):509-22.

\section{Publisher's Note}

Springer Nature remains neutral with regard to jurisdictional claims in published maps and institutional affiliations. 